\title{
Urothelial carcinoma with paraneoplastic leukocytosis
}

\author{
$\mathrm{CW} \mathrm{Hsu}, \mathrm{HY} \mathrm{Su}$ *
}

Hong Kong Med J 2017;23:207.e3-4

DOI: 10.12809/hkmj164956

An 88-year-old male with no underlying disease presented to our emergency department in March

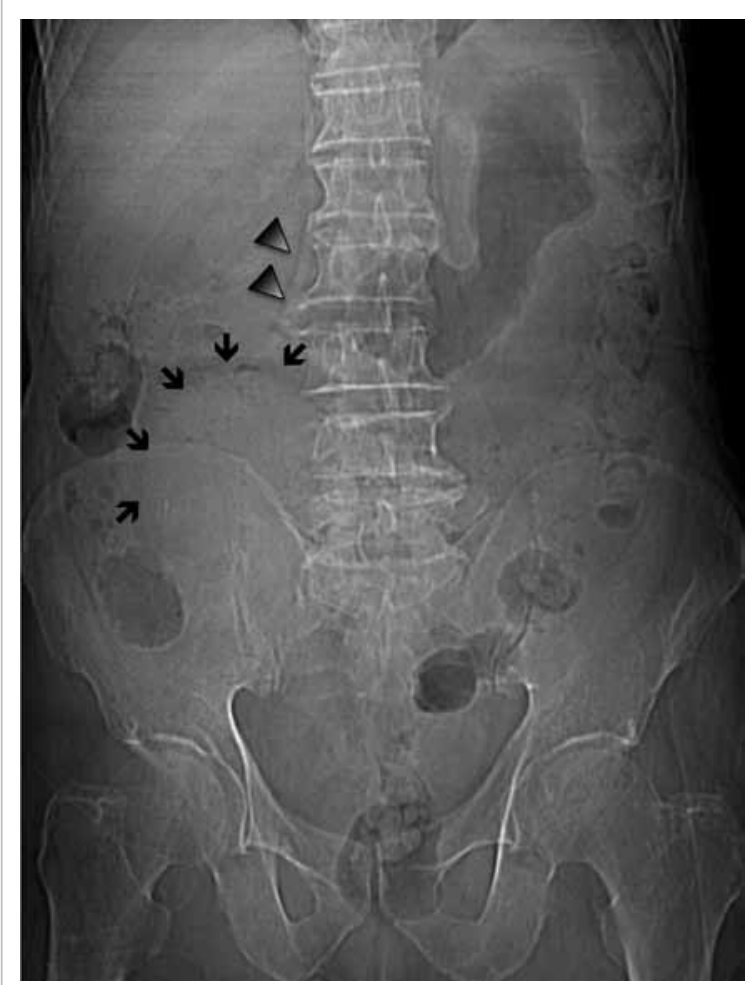

FIG I. A plain abdominal film revealing a mass lesion (arrows) with obliteration of right lower psoas shadow (arrowheads)

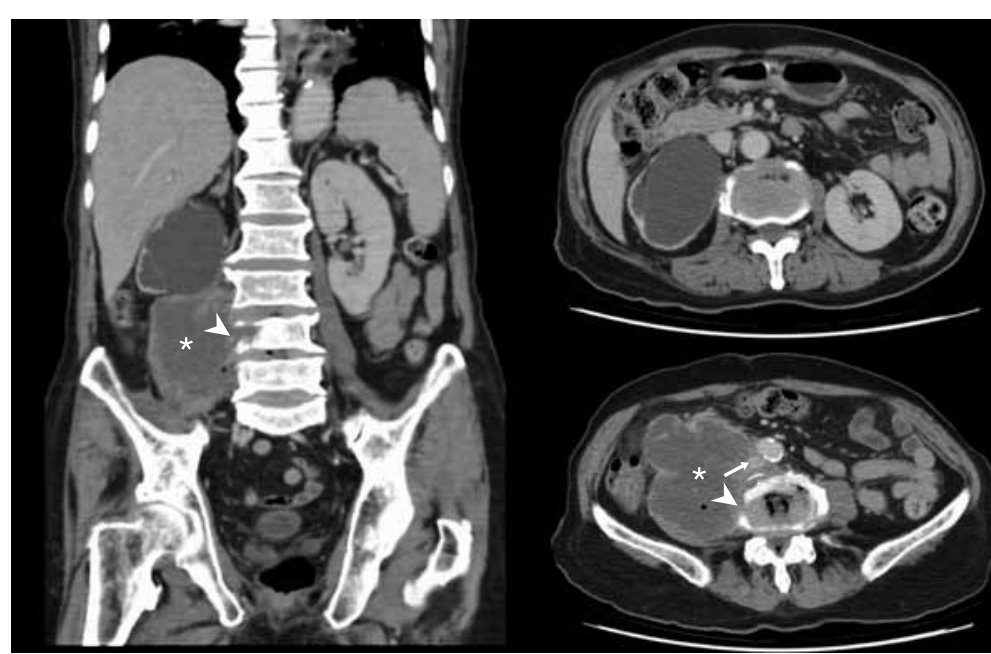

FIG 2. Abdominal computed tomographic scans demonstrating a cyst-like lesion with irregular surface (asterisk) that involves the adjacent psoas muscle, vertebral body (arrowhead), ureter, and great vessels (arrow) in the retroperitoneal cavity
2015 with a 2-week history of right flank pain but no fever or urinary tract symptoms. He was conscious, alert, and well-oriented. His blood pressure was $145 / 89 \mathrm{~mm} \mathrm{Hg}$, with a heart rate of 82 beats/min and respiratory rate of 16 breaths/min on arrival. Physical examination revealed obvious right flank knocking tenderness. Laboratory testing revealed white blood cell (WBC) count of $34.7 \times 10^{9} / \mathrm{L}$ (reference range [RR], 4.5-11.0 x 109/L), haemoglobin level of $95 \mathrm{~g} / \mathrm{L}$ (RR, 135-175 g/L), platelet count of $496 \times 10^{9} / \mathrm{L}$ (RR, $\left.150-450 \times 10^{9} / \mathrm{L}\right)$, C-reactive protein level of 24.3 $\mathrm{mg} / \mathrm{L}(\mathrm{RR}, 0-10 \mathrm{mg} / \mathrm{L})$, and serum calcium level of $3.31 \mathrm{mmol} / \mathrm{L}$ (RR, 2.18-2.58 $\mathrm{mmol} / \mathrm{L})$. Urinalysis demonstrated no pyuria, but 50 to 75 red blood cells per high-power field. Prothrombin time, activated partial thromboplastin time, and fibrinogen were within normal limits. An abdominal plain film revealed a mass lesion with a concealing right lower psoas shadow (Fig 1). Subsequent abdominal computed tomographic (CT) scan demonstrated a cyst-like lesion with irregular surface, involving adjacent tissues in the retroperitoneal cavity (Fig 2).

A CT-guided biopsy was performed because the discrepancy between clinical presentation and laboratory tests and image study made it difficult for physicians to discriminate psoas muscle abscess from malignancy. Ultimate pathology of biopsy specimens revealed a high-grade urothelial carcinoma with tumour necrosis. The TNM staging was stage IV (cT4NOM0). Blood and urine cultures were all negative. Follow-up 1 month later revealed a WBC count of $34.7 \times 10^{9} / \mathrm{L}$.

Urothelial carcinoma originates in the urinary system. Paraneoplastic leukocytosis, defined by a WBC count of $>20.0 \times 10^{9} / \mathrm{L}$ on more than two occasions 30 days apart, occurs in $0.6 \%$ of urothelial carcinoma cases. ${ }^{1}$ The aetiology of paraneoplastic leukocytosis is considered to be related to the production of granulocy te colony-stimulating factor by tumour cells. ${ }^{2,3}$ Hypercalcaemia, anaemia and thrombocytosis, as seen in this case, are also frequently seen in paraneoplastic syndrome. It is associated with advanced urothelial cancer and indicates a poor prognosis. ${ }^{1,3}$ Muscle invasion is also frequently found in cases of urothelial cancer with paraneoplastic leukocytosis. ${ }^{1}$ The cyst-like pattern of urothelial cancer on abdominal CT scan in combination with the paraneoplastic leukocytosis can mislead physicians into making an incorrect diagnosis, such as pyogenic psoas muscle abscess. We advise physicians to always 
be aware of urothelial cancer with paraneoplastic leukocytosis while managing a cyst-like lesion in the retroperitoneal cavity.

CW Hsu, MD, PhD

HY Su *, MD

Department of Emergency Medicine, E-Da Hospital and I-Shou University, Kaohsiung, Taiwan

Previously presented at the 8th Asian Conference on Emergency Medicine, Taiwan, 7-10 November 2015.

* Corresponding author: hys927@hotmail.com

\section{References}

1. Izard JP, Gore JL, Mostaghel EA, Wright JL, Yu EY. Persistent, unexplained leukocytosis is a paraneoplastic syndrome associated with a poor prognosis in patients with urothelial carcinoma. Clin Genitourin Cancer 2015;13:e253-8.

2. Ito N, Matsuda T, Kakehi Y, Takeuchi E, Takahashi T, Yoshida O. Bladder cancer producing granulocyte colonystimulating factor. N Engl J Med 1990;323:1709-10.

3. Kumar AK, Satyan MT, Holzbeierlein J, Mirza M, Van Veldhuizen P. Leukemoid reaction and autocrine growth of bladder cancer induced by paraneoplastic production of granulocyte colony-stimulating factor-a potential neoplastic marker: a case report and review of the literature. J Med Case Rep 2014;8:147. 